\title{
ESPÍRITO SANTO, PROFECIA E PLENITUDE NAS ESCRITURAS JUDAICAS
}

\author{
Edgard Leite Ferreira Neto* \\ Universidade do Estado do Rio de Janeiro - UERJ \\ edleiteneto@yahoo.com.br
}

\begin{abstract}
RESUMO: O Espírito de Deus é identificado em diversos momentos centrais da literatura bíblica hebraica. Propicia a distinção do povo de Israel, do judeu e do profeta, dos outros povos e pessoas, e, portanto, é um elemento separador. A literatura profética assinala, no entanto, um futuro de redenção, no qual todos serão tocados por esse mesmo Espírito. O Espírito, de forma paradoxal, separa mas também permite transcender a separação. Na literatura posterior à Bíblia hebraica fica claro o poder do Espírito em perdoar, e portanto reunir, os pecadores aos justos. Nos textos rabínicos, o estágio superior na vivência do Espírito está relacionado "ao mundo que virá", ou ao retorno de Elias, o advento do Messias e a ressurreição dos mortos. Isto é, a plenitude do Espírito. Onde se instalará a Paz, o Bem e a Salvação, numa dimensão universal.
\end{abstract}

PALAVRAS-CHAVE: Judaísmo rabínico- Espírito Santo- Profecia.

\section{HOLY SPIRIT, PROPHECY AND FULLNESS IN THE JEWISH SCRIPTURES}

\begin{abstract}
The Holy Spirit is identified in several key moments of the Hebrew Bible literature. Provides the distinction of Israel, the Jewish and the prophet, of other peoples and people, and therefore is a separator element. Prophetic literature points out, however, a future of redemption, in which everyone will be touched by the Spirit of God. The Spirit, paradoxically, separates and allows transcend the separation. In intertestamental literature it is clear the power of the Spirit to forgive and therefore gather sinners to the righteous. In rabbinic texts, the upper stage in the experience of the Spirit is related "to the world to come", or the return of Elijah, the advent of the Messiah and the resurrection of the dead, the fullness of the Spirit. Where will be peace, good and salvation, in a universal dimension.
\end{abstract}

KEYWORDS: Rabbinic Judaism, Holy Spirit, prophecy.

* Diretor Executivo do Instituto Realitas, Vice-Presidente e Membro Titular da Academia Brasileira de Filosofia (cadeira no. 4, Patrono: Alceu Amoroso Lima), Doutor e Mestre em História pela Universidade Federal Fluminense e integrante do Conselho Administrativo da Sociedade Internacional de Estudos Jesuítas (Paris). É Professor Extraordinário do Curso de Doutoramento em Estudos Globais da Universidade Aberta, Lisboa. Professor Associado de História da Universidade do Estado do Rio de Janeiro - UERJ e Adjunto IV da Universidade Federal do Estado do Rio de Janeiro UNIRIO. 


\section{INTRODUÇÃo}

Na tradição judaica a expressão ㅁำ, Ruah, "espírito, vento, hálito, sopro", adquiriu, ao longo dos séculos, um sentido polissêmico. O que expressava, como veremos, a sua realidade na literatura bíblica. De forma diferente ocorreu na tradição cristã que, desde muito cedo, buscou a sua precisão conceitual. $\mathrm{O}$ que não quer dizer que não expresse, igualmente, a sua realidade.

Mesmo porque sua polissemia sempre foi percebida através do reconhecimento de seu papel transformador, como expansão da consciência divina. De uma sutil essência que adentra no mundo e que contém valores, inspirações e realidades que expressam a presença de Deus.

Neste estudo pretendemos discutir como, na tradição bíblica e rabínica o tema foi entendido em seu papel separador, aglutinador e redentor.

\section{O ESPÍRITO DE DEUS}

O Espírito de Deus emerge, como agente, na literatura bíblica, em seu

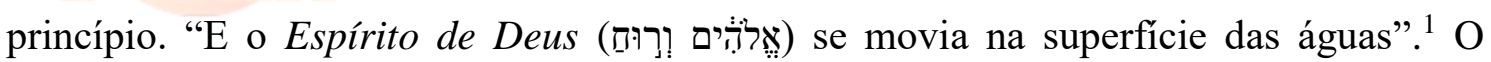
Talmude, talvez hesitando, segundo Ginzberg ${ }^{2}$, diante de uma provável perspectiva cristã sobre o assunto, preferiu entender Ruah, traduzindo ao aramaico, como "vento" e não como "espírito". 3

Tal entendimento, entretanto, também decorre do fato de que as primeiras ações de Deus, "no princípio", foram de separação. Dia e noite, "águas das águas", terra e mares. E tal ação se repetirá no Êxodo, exatamente por intermédio do vento: "E Deus, por um forte vento oriental (...) fez o mar se retirar (...) e as águas foram divididas". ${ }^{4}$ Então o espírito é também vento.

1 Genesis 1:2 . Bíblia de Jerusalém. São Paulo, Paulus, 2004.

2 GINZBERG, Louis: Legends of the Jews. Vols. I[1909] Philadelphia, Jewish Publication Society, 2003. p. 7

3 Hagigah in Epstein, I (ed.): Hebrew-english edition of the Babylonian Talmud. London, Soncino Press, 1990, 12 a.

4 Êxodo 14:21. Bíblia de Jerusalém. São Paulo, Paulus, 2004. 
Ruah tem, às vezes, o sentido de "lado", o que também sugere a ideia de separação. E, de fato, grande parte da obra do Espírito de Deus na literatura bíblica está no movimento de separar. Por exemplo, o sagrado do profano.

O Espírito Santo, explicitamente denominado como tal, está presente em outros momentos centrais da literatura bíblica hebraica.

Nos Salmos, existe o pedido: "não me rejeites para longe de sua face, não

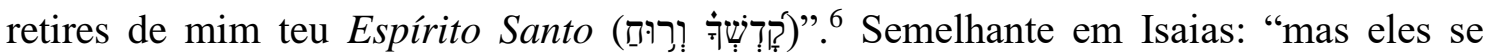
rebelaram e magoaram o seu Espírito Santo". 7

O Espírito Santo, portanto, na perspectiva bíblica, pode estar presente nos seres humanos, ou no ser, e nele apresenta uma realidade constante, seja de forma circunstancial ou essencial. Embora separe o povo de Israel, ou o judeu, dos outros povos e pessoas, e, portanto, seja estruturante, nem sempre, no entanto, possui uma dinâmica estável.

A sua permanência não é certa, ele pode se retirar, e grande parte da angústia humana bíblica diante de Deus está centrada na possível ruptura dessa presença ou na necessidade de retomá-la, ou de experimentá-la nova e plenamente. Nessa dinâmica parece estar presente o eco da dolorosa separação verificada quando da expulsão do Jardim do Éden.

Saul, quando chegou a Gabaá, "um grupo de profetas veio ao seu encontro; o

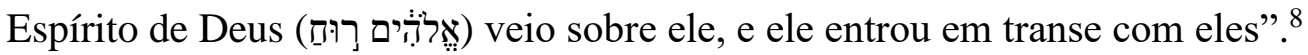

Ruah Elohim também separa, aqui, aqueles que recebem a profecia dos que não a recebem. "Então", explica o Profeta Samuel, “o Espírito de Deus (Ruah Adonai) virá sobre ti, entrarás em transe com eles e te transformará em outro homem". 9

Tal separação fundamenta a realidade social e política dos profetas. Em Neemias por exemplo, aponta-se esse papel identificador do Espírito: "advertiste-os pelo teu Espírito por intermédio dos Profetas". ${ }^{10}$ Os profetas são agentes do Espírito.

\footnotetext{
JASTROW, Marcus: Dictionary of Targumim, Talmud, and Midrashic Literature. 1926.

6 Salmo 51:11. Bíblia de Jerusalém. São Paulo, Paulus, 2004.

7 Isaias 63:10-11. Bíblia de Jerusalém. São Paulo, Paulus, 2004.

81 Samuel 10:10. Bíblia de Jerusalém. São Paulo, Paulus, 2004

91 Samuel 10:6. Bíblia de Jerusalém. São Paulo, Paulus, 2004.

10 Neemias 9:30 . Bíblia de Jerusalém. São Paulo, Paulus, 2004.
} 
E assim também se dará com o Messias: “um ramo sairá do tronco de Jessé, um rebento brotará de suas raízes. Sobre ele repousará o Espírito de Deus" ${ }^{11}$ O Espírito de Deus é, assim, experiência profética, ou espírito de sabedoria, inteligência, conselho, fortaleza, conhecimento e temor a Deus (Is 11:2) (et pietatis, "e de piedade", acrescenta a Vulgata).

O Espírito abre, com sua presença, a realidade de uma vida plena, que inclui a visão profética, mas também o discernimento. Como diz o Livro dos Provérbios, "Se acatarem a minha repreensão, eu darei a vocês um espírito e revelarei a vocês os meus pensamentos". 12

O Espírito é também a própria vida em essência. Assim, lê-se nos Salmos: "retiras sua respiração (רָָּּם) e eles expiram (...) envias teu sopro e eles são criados". ${ }^{13}$ O espírito separa, assim, de uma forma mais fundamental, também, a vida da morte.

Mas separa, apenas? No livro do profeta Joel, a futura era messiânica, o fim da jornada da história, é entendida como integradora: "Depois disto, derramarei meu espírito sobre toda carne. Vossos filhos e vossas filhas profetizarão, os anciãos terão sonhos, os jovens terão visões. Até sobre os servos e as servas, naqueles dias, derramarei o meu espírito". ${ }^{14}$

O que expressa um desejo primeiro de Moisés: "Quem dera todo o povo de Deus fosse profeta, dando-lhe Deus o seu espírito". ${ }^{15}$

A literatura profética assinala assim um futuro de redenção, no qual todos serão tocados pelo Espírito de Deus. Sem o temor da perda e superando toda divisão. "Com efeito, minha casa será chamada de casa de oração para todos os povos" ${ }^{16} \mathrm{O}$ Espírito, portanto, de forma paradoxal, separa e une.

\section{O ESPÍRITO EXPIADOR}

\footnotetext{
11 Isaias 11:1-12. Bíblia de Jerusalém. São Paulo, Paulus, 2004.

12 Livro dos Provérbios 1: 23. Bíblia de Jerusalém. São Paulo, Paulus, 2004.

13 Salmos 104: 29-30. Bíblia de Jerusalém. São Paulo, Paulus, 2004.

14 Joel 2:29-29. Bíblia de Jerusalém. São Paulo, Paulus, 2004.

15 Neemias 11:29 . Bíblia de Jerusalém. São Paulo, Paulus, 2004.

16 Isaias 56:7. Bíblia de Jerusalém. São Paulo, Paulus, 2004.
} 
A literatura pós bíblica, que conhecemos também através dos manuscritos de Qumram, atesta a grande importância dada ao tema do Espírito, nos momentos que antecedem o universo do Novo Testamento.

Não cabe aqui uma discussão sobre as origens dessa literatura. No entanto, devemos anotar que parte desses textos estão associados a tendências religiosas que criticavam as políticas e atitudes da dinastia dos hasmoneus e da dinastia herodiana, e estavam imbuídas de expressivas crenças apocalípticas e messiânicas.

Na Regra da Comunidade (1QS), texto que contêm a disciplina da congregação de sectários que supostamente existiu em Qumran, fala-se que é pelo "Espírito Santo da comunidade, em sua verdade, que a pessoa é limpa de todas suas iniquidades". ${ }^{17}$

No Hino de Ação de Graças (1QHa), também é colocada essa dimensão purificadora do Espírito: "purifica-me com teu Espírito Santo, para levar-me a ti, pela tua vontade, de acordo com a extensão de tua bondade". ${ }^{18}$

Assim, o Espírito Santo adquire uma dimensão expiatória. Por ele os "separados" são reunidos. Os pecadores, redimidos. Os estranhos, integrados.

No assim chamado Documento de Damasco, do qual há vários fragmentos em Qumram, afirma-se que "os ungidos", no caso os Messias de Aarão e Israel (acompanhando a perspectiva da duplicidade da aparição messiânica) apresentam essa presença do Espírito Santo (4Q266 2 II:12). Por conta dessa presença eles detém o poder de expiação dos pecados (CD-B XIV:19).

Em Seus movimentos, em Sua presença, o Espírito Santo realiza separações e permite a identificação do pecado, e da solidão que este traz ao ser diante de Deus. Num caso extremo, como vimos, sua ausência assinala a inexistência. ou a morte. Mas também, nessa literatura, o elemento messiânico é considerado como o vetor das perspectivas integradoras e redentoras do Espírito, através de suas características mais essenciais, seus dons.

\section{O ESPÍRITO NA LITERATURA RABÍNICA.}

\footnotetext{
17 1QS III:6

18 1QHa VIII:19
} 
O poder redentor do Espírito foi igualmente reconhecido na literatura talmúdica. Os rabinos irão admitir que Deus busca sempre estabelecer sua presença no mundo. De forma contínua, e insistente. Segundo Jacob Neusner, isso se dá tanto através "de intermediários", como os anjos, quanto através da realização dos "atributos divinos, por exemplo o Espírito Santo ou a Shekhinah". ${ }^{19}$

A experiência do Espírito Santo foi entendida, nesse sentido, como sendo sedimentada pela boa fé: segundo Neusner, "a verdadeira e benevolente intencionalidade de Deus", deve harmonizar-se com a completa sinceridade do ser, o que, segundo os rabinos. "torna a pessoa plenamente capaz de encontrar o Espírito Santo, porque ela dirige ao Espírito Santo ou a Deus a mesma atitude de correta intenção que Deus valoriza". ${ }^{20}$

O Talmude, no entanto, acrescenta, como elemento presente no recebimento do Espírito, não apenas a boa fé, mas também a alegria. Discutindo os problemas teológicos do Eclesiastes, e suas aparentes contradições, explicou o Rabino Simeon ben Zoma:

\begin{abstract}
'a raiva é melhor que o riso' a raiva que o Sagrado, abençoado ele seja, dirige aos justos neste mundo é melhor que o riso que o Sagrado, abençoado Ele seja, dirige aos malvados neste mundo. 'E eu digo do riso, que é para ser louvado' se refere ao riso que o Sagrado, abençoado Ele seja, compartilha com o justo no mundo que virá. 'Assim, eu celebro a alegria' (...) porque a Presença Divina repousa sobre o homem não através da melancolia, nem na preguiça, nem na frivolidade, nem nas conversas tolas, mas sim através da alegria em conexão com um preceito, como foi dito:" e o Rabino cita 2 Reis, 3:15: "trazei-me agora um músico. $\mathrm{E}$ aconteceu que, enquanto o músico tocava, a mão do Senhor veio sobre ele. ${ }^{21}$
\end{abstract}

Nesta passagem está claro que a alegria de executar um preceito, uma mitsvá, uma determinação divina, é também caminho para o recebimento e experiência do

19 NEUSNER, Jacob (c): "Messiah in Rabbinic Judaism" .In: NEUSNER, Jacob et alii: The Encyclopaedia of Judaism. Vol. IV. Brill, Leiden, 2005. pp.77-78

20 Melkhita XXVI:26 apud NEUSNER, Jacob (b): "Intentionality in Judaism”. In: NEUSNER, Jacob et alii: The Encyclopaedia of Judaism. Vol. II. Brill, Leiden, 2005, p.303.

21 Shabbat in Epstein, I (ed.): Hebrew-english edition of the Babylonian Talmud. London, Soncino Press, 1990, p.30b. 
Espírito Santo. Como está em Provérbios, 1:23. O prazer da música, por exemplo, é caminho para Deus.

Sobre esse assunto, concordaria o Rabino Pinchas Ben Yair, na Mishná, quando também afirma o caminho da observância do preceito para alcançar o sentimento redentor decorrente da presença do Espírito Santo:

A observância conduz à limpeza, a limpeza leva à abstinência, a abstinência leva à santidade, a santidade leva à modéstia. Modéstia leva ao medo do pecado, o medo do pecado leva à piedade, a piedade leva ao Espírito Santo, o Espírito Santo leva à ressurreição dos mortos, e a ressurreição dos mortos vem por intermédio de Elias, bendita seja sua memória. ${ }^{22}$

Cabe anotar aqui que ambos Rabinos, Simeon ben Zoma e Pinchas ben Yair, entendem que a presença do Espírito Santo, sua vivência e plenitude, está relacionada às atitudes corretas que os homens tomam na vida, o que os deve aproximar dos mandamentos de Deus e de sua essência. Em tudo, um processo de elevação espiritual contínuo, fundamentado nas palavras de Deus.

Na tradição cabalista, como anotou Gerson Scholem, alcançar a experiência da plenitude do Espírito Santo e da profecia, devekut, é também a maior das realizações místicas. $^{23}$

No entanto, como podemos perceber, tanto o Rabino Simeon quanto o Rabino Pinchas, acompanhando as visões messiânicas dos profetas e as milenares angústias de redenção do povo judeu, entendem que o estágio superior na vivência do Espírito está relacionado "ao mundo que virá" (ha olam habba), ou ao retorno de Elias, o advento do Messias e a ressurreição dos mortos.

E não parece haver dúvidas que a mais essencial alegria, para o Rabino Simeon, é o riso que compartilhamos com Deus no "mundo que virá", e que para o Rabino Pinchas, há uma estreita ligação entre o Espírito Santo e Elias, pois "a piedade leva ao Espírito Santo, o Espírito Santo leva à ressurreição dos mortos, e a ressurreição dos mortos vem por intermédio de Elias". Como é Elias que anuncia o Messias, é o Messias obra direta do poder do Espírito Santo.

22 Mishna Sotah, 9:15 apud HÜTTERMANN, Aloys: “Hygiene in Rabbinic Judaism”. In: NEUSNER, Jacob et alii: The Encyclopaedia of Judaism. Vol. II. Brill, Leiden, 2005. p.274

23 SCHOLEM, Gershom (b): Kabbalah. New York, Meridian, 1978, p. 174 
A vivência do Espírito, neste mundo, está ligada a um processo que busca a sua plenitude, o que também coloca, portanto, o tema de uma utopia espiritual futura como um tema por excelência do judaísmo rabínico.

Como bem colocou Neusner, “é esta uma doutrina necessária para um sistema que insiste na racionalidade da ordem do universo sob o controle de Deus". ${ }^{24}$ Há um plano de Deus para o mundo, e esse plano objetiva a redenção humana.

\section{O Espírito Santo, Elias, o Messias.}

A figura espiritual de Elias e a transcendente personalidade do Messias estão, nas tradições judaicas, envoltas em um enigma nebuloso, em torno do qual gravitam, de forma um tanto aleatória, as expectativas de redenção. E por ter uma dinâmica intrinsecamente misteriosa, tal enigma nunca propiciou a formulação de uma assertiva doutrinária clara, de reconhecimento geral.

Por isso Neusner foi cauteloso ao caracterizar o judaísmo rabínico como uma religião messiânica. ${ }^{25}$ No entanto, em que pese essa opinião, "o mundo que virá" (ha olam habba) desempenha um papel central na escatologia judaica. A vivência do Espírito Santo, sua realização e plenitude, está absolutamente associada a esse momento futuro.

No Talmude existe uma breve discussão sobre a cronologia da redenção, e portanto sobre a data do advento deste mundo do Espírito. Cita-se um livro, o Tanna Devei Eliyahu, que é atribuído a revelações do próprio Profeta Elias. Neste, foi estabelecido que

o mundo existirá por seis mil anos: os dois mil primeiros anos foram vazios [sem a Lei] os seguintes dois mil anos são o período da Torá [iniciados com a chegada de Abraão e Sara em Haran] e os próximos dois mil anos são o período do Messias. Infelizmente "por conta de nossos inúmeros pecados, algo desse número já passou, e o Messias ainda não veio". ${ }^{26}$

24 SCHOLEM, Gershom (b): Kabbalah. New York, Meridian, 1978, p.169

25 NEUSNER, Jacob (c): Messiah in Rabbinic Judaism. In NEUSNER, Jacob et alii: The Encyclopaedia of Judaism. Vol. IV. Brill, Leiden, 2005. p. 1707

26 Avodah Zarah in Epstein, I (ed.): Hebrew-english edition of the Babylonian Talmud. London, Soncino Press, 1990, p.9a 


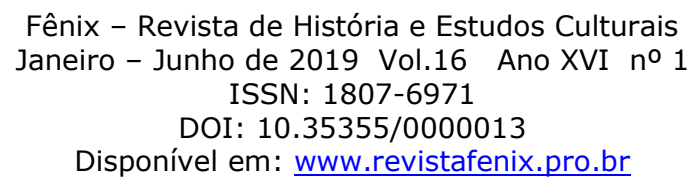

Essa visão tripartida da história (o texto do Talmude é anterior ao século V) implica na crença de que os acontecimentos no tempo possuem um sentido, determinado por Deus. Este sentido corresponde à dinâmica bíblica de pecado, punição, arrependimento e perdão, deslocado para um plano maior de eventos.

$\mathrm{Na}$ perspectiva cabalista, por exemplo, no tratado medieval Temunah, foi desenvolvida a doutrina dos ciclos do mundo, ou dos Shemittoth, na qual tal sucessão de momentos foi entendida, de forma mais de acordo com a doutrina cabalística das sefirot, como sete ciclos de sete mil anos, num total de 49.000 anos.

Nestes, diferentes potências de Deus se manifestariam de forma específica, todas no sentido de propiciar o retorno da existência ao divino. No final desses 49.000 anos, "um ano [de Deus] de jubileu", ou seja, mil anos, acompanharia o retorno das coisas ao seu início. Completar-se-ia a marca de um grande ciclo de 50.000 anos. Gershom Scholem também viu aqui similitudes com as visões utópicas de Joachim de Fiore, principalmente no sentido de um movimento progressivo do Espírito no sentido da utopia. ${ }^{27}$

A utopia rabínica trabalha, em linhas gerais, com o Messias. Mmas o preciso papel dele, e a forma como ele se movimenta no mundo é envolvida em divergências visionárias. Não é ele, certamente, que ressuscitará os mortos. "É Deus quem os fará respirar". 28

\section{O ESPÍRITO E A REDENÇÃO.}

"O tempo do Messias é um tempo de redenção". ${ }^{29}$ O mesmo ocorre na literatura cristã, no Apocalipse, pois momento que precede o retorno de Jesus Cristo é um tempo de separação e ausência, extremas, de Espírito. Numa coleção midráshica medieval, o Peshiqta Rabati, é dito que:

[disse o Rabino Yohanan:] 'na geração na qual o filho de David vier, os discípulos dos sábios perecerão, e aqueles que permanecerem terão visão fraca (...) terríveis coisas virão para as pessoas' (...) [disse o

27 SCHOLEM, Gershom (a): Origins of The Kabbalah. Princenton, 1987. p.478-484

28 NEUSNER, Jacob (c): Messiah in Rabbinic Judaism. In: NEUSNER, Jacob et alii: The Encyclopaedia of Judaism. Vol. IV. Brill, Leiden, 2005. p. 1706

29 Ibid., p. 1707 


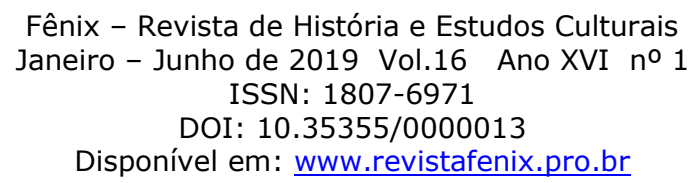

Rabino Abun:] 'os lugares de encontro serão prostíbulos' (...) [disse o Rabino Nehorai:] 'jovens humilharão os velhos, (...) um filho não se envergonhará por seu pai' [disse o Rabino Abba bar Kahana:] 'o filho de David virá somente a um geração preparada a sofrer total extermínio' [disse o Rabino Yannai:] 'o filho de David virá somente a uma geração cujos líderes serão como cães'. ${ }^{30}$

A desagregação, a descrença, o império da vaidade e do egoísmo, a ausência da percepção da Verdade, todos esses elementos assinalam a proximidade de uma transformação absoluta do mundo. Como na história bíblica do povo judeu, na situação extrema de desamparo delineia-se, no entanto, a presença do Espírito.

A reconstrução do Templo de Jerusalém é um dos momentos centrais da obra messiânica. Esta se segue às grandes guerras contra os povos de Gog e Magog e à ressurreição dos mortos. "Assim, as consequências da rebelião e do pecado serão superadas, a luta entre os desejos do homem e a palavra de Deus resolvida”. Advirá a "restauração do equilíbrio, da ordem, da proporção, da eternidade". 31

Vários textos midráshicos medievais registram visões desse momento futuro. No Peshikta Rabati, le-se que:

O trabalho de Elias começará três dias antes do advento do Messias. Ele aparecerá na Palestina e erguerá um lamento sobre a destruição da Terra Santa, e sua voz será ouvida por todo mundo. As últimas palavras de seu discurso serão 'Agora a paz virá sobre a terra'. No segundo dia, ele aparecerá de novo e proclamará 'O Bem virá sobre a terra'. E no terceiro dia, sua promessa será ouvida: 'A salvação virá sobre a terra' ${ }^{32}$

Então, segundo o Otot ha-Mashiah, "a Anjo Miguel soará a trombeta, e mais uma vez Elias aparecerá, desta vez para introduzir o Messias". ${ }^{33}$

\section{A CULMINÂNCIA DA OBRA dO ESPÍRITO.}

30 Peshikta Rabbati apud NEUSNER, Jacob (c): Messiah in Rabbinic Judaism. In: NEUSNER, Jacob et alii: The Encyclopaedia of Judaism. Vol. IV. Brill, Leiden, 2005. p. 1702

31 NEUSNER, Jacob (c): Messiah in Rabbinic Judaism. In: NEUSNER, Jacob et alii: The Encyclopaedia of Judaism. Vol. IV. Brill, Leiden, 2005.. p.1693

32 Peshikta Rabati in GINZBERG, Louis: Legends of the Jews. Vol. II [1909] Philadelphia, Jewish Publication Society, 2003. p.1021

33 Otot ha-Massiah in GINZBERG, Louis: Legends of the Jews. Vol. II [1909] Philadelphia, Jewish Publication Society, 2003. p.1021 
O Espírito de Deus, presente no princípio, "E o Espírito de Deus se movia na superfície das águas” (Gn 1:2) também se apresenta, assim, no final.

A utopia rabínica, tão complexa e, eventualmente, obscura, não deixa de apontar, no "mundo que virá", holam habba, essa presença preocupada, misteriosa, que restabelece ao ser a sua integridade, numa dimensão maior e profunda. Concede o dom da profecia e da vida eterna.

O sentido, para o povo de Israel, parece ser o de que, durante esse misterioso momento, ele alcançará a paz com todos os povos e os seres humanos viverão sem guerras e em alegrias. E por isso, segundo o Peshikta Rabati, diz Elias, no primeiro dia: 'Agora a paz virá sobre a terra'.

No entanto, no interior desse mistério histórico, que encontra na restauração do Templo de Jerusalém destruído um momento icônico, há um outro mistério, mais essencial e literariamente difuso, que é "o derramamento do espírito sobre toda carne. Vossos filhos e vossas filhas profetizarão, os anciãos terão sonhos, os jovens terão visões". ${ }^{34}$

A salvação é ampla e se estende para além das partes, integrando no conhecimento de Deus toda a humanidade e, talvez, todas as formas vivas, e a natureza como um todo, como sugere Isaias, de forma alegórica: “então o lobo morará com o cordeiro, e o leopardo se deitará com o cabrito. O bezerro, o leãozinho e o gordo novilho andarão juntos, e um menino pequeno os guiará". 35

Sugere-se aqui uma superação ou integração de oposições e uma extensão dessa lógica a todas as forma viventes. Por isso, segundo o Peshikta Rabati, diz também Elias, no segundo dia: 'O Bem virá sobre a terra'.

E, por fim, há um terceiro mistério, que diz respeito à própria natureza do Espírito, sua essencialidade: "retiras tua respiração e eles expiram (...) envias teu sopro e eles são criados". ${ }^{36}$

A presença do Espírito assinala a plenitude da presença divina, a superação da morte, a vida eterna. E, por isso, assim se acredita, dirá Elias, no terceiro dia: 'A salvação virá sobre a terra'.

\footnotetext{
34 Joel, 2: 28-29. Bíblia de Jerusalém. São Paulo, Paulus, 2004.

35 Isaias 11:6. Bíblia de Jerusalém. São Paulo, Paulus, 2004.

36 Salmos 104 :29-30. Bíblia de Jerusalém. São Paulo, Paulus, 2004.
} 


\section{CONCLUSÕeS}

A trajetória do Espírito Santo, na literatura bíblica e talmúdica, é, em grande medida, uma reflexão infinita sobre um conceito impreciso, mas que é entendido como a expressão de um aspecto crucial da presença de Deus no mundo.

O movimento de Deus na organização da realidade, um movimento que, ao dividir, estabelece os limites dos fenômenos e suas particularidades, ou seja, funda o próprio universo visível, foi considerado como contendo, igualmente, a dinâmica que o integra e harmoniza, ao permitir a transcendência das suas divisões aparentes. Ou seja, que propicia a redenção desses mesmos limites, fundadores do mundo: judeus e gentios, luz e trevas, vida e morte.

A caracterização desse Espírito como a alegria, ou como a sensibilidade musical, aponta a recorrente ideia de que é possível, necessário, ou talvez contingente, à consciência, o estabelecimento de conexões com essa dimensão maior ou subjacente. Tal percepção funda-se em valores ou sentimentos subjetivos, interiores, cujos limites são imprecisos, mas que se confundem com limites invisíveis e divinos.

A percepção contínua dessa realidade, pela tradição, estabelece a integridade de uma doutrina, que, mesmo sendo inconstante, assegura, na razão e na interioridade que permite o seu reconhecimento em diferentes momentos históricos, que a fragmentação do mundo na verdade não é fragmentação, mas modo de integração. E que longe de assegurar a realidade da morte, ou da vida, apenas sinaliza a permanência absoluta da eternidade. 
Fênix - Revista de História e Estudos Culturais

ISSN: $1807-6971$

DOI: $10.35355 / 0000013$

Disponível em: www.revistafenix.pro.br 